\title{
BIOINFORMATION
}

Discovery at the interface of physical and biological sciences

\section{Molecular docking analysis of $\alpha 2$-containing GABAA receptors with benzimidazoles derivatives}

\author{
Abdellatif Bouayyadi1 ${ }^{*}$, Aissam El Aliani ${ }^{1}$, Yassine Kasmi $^{1}$, Ahmed Moussaif ${ }^{1}$, Najia El Abbadi ${ }^{1}$, \\ Abdelhalim Mesfioui ${ }^{2}$, El Mokhtar Essassi ${ }^{3}$, Mohammed El Mzibri' ${ }^{1}$ \\ 1Division of Life Sciences, National Centre for Energy, Nuclear Sciences and Techniques (CNESTEN), Morocco; ${ }^{2}$ Laboratory of Genetic, \\ Endocrinology and Biotechnology-Faculty of Sciences, Ibn Tofaïl University, Morocco; ${ }^{3}$ Moroccan Foundation for Advanced Sciences, \\ Innovation and Research. Morocco; BOUAYYADI Abdellatif - Phone: +212679889665; E-mail address: abdellatif_bouayyadi@yahoo.fr \\ *Corresponding authors
}

E-mail contacts: Abdellatif Bouayyadi - abdellatif_bouayyadi@yahoo.fr; Aissam El Aliani - elalianiaissam@gmail.com; Yassine Kasmi kasmi.yassin@gmail.com; Ahmed Moussaif - ahmou2010@gmail.com; Najia El Abbadi - najiaelabbadi@yahoo.fr; Abdelhalim Mesfioui a.mesfioui@yahoo.fr; El Mokhtar Essassi - emessassi@yahoo.fr; Mohammed El Mzibri - mzibri@yahoo.com

Received July 4, 2020; Revised July 8, 2020; Accepted July 10, 2020; Published August 31, 2020

DOI: $10.6026 / 97320630016611$

Declaration on Publication Ethics:

The authors state that they adhere with COPE guidelines on publishing ethics as described elsewhere at https://publicationethics.org/. The authors also undertake that they are not associated with any other third party (governmental or non-governmental agencies) linking with any form of unethical issues connecting to this publication. The authors also declare that they are not withholding any information that is misleading to the publisher in regard to this article.

Declaration on official E-mail:

The corresponding author declares that official e-mail from their institution is not available for all authors

The authors are responsible for the content of this article. The Editorial and the publisher has taken reasonable steps to check the content of the article with reference to publishing ethics with adequate peer reviews deposited at PUBLONS.

\begin{abstract}
:
It is of interest to study the binding capacity of "3-[2-(2-Amino-1H-benzo[d]imidazol-1-yl)ethyl]-1,3-oxazolidin-2-one" (OXB 2 ) with the active site of gamma-aminobutyric acid (GABA) located in the GABA type A receptor (GABA $\mathrm{R}$ ) in comparison with different GABA subtypes. Optimal binding features were observed with the $\alpha_{2} \beta_{2} \gamma_{2}$ isoform $(-8 \mathrm{kcal} / \mathrm{mol})$. This is similar $(-7.3$ and $-7.2 \mathrm{kcal} / \mathrm{mol}$, respectively) for subtypes $\left(\alpha_{3} \beta_{2} \gamma_{2}\right.$ and $\left.\alpha_{1} \beta_{2} \gamma_{2}\right)$. This implies that $\mathrm{OXB}_{2}$ binds preferentially to subtypes associated with anxiety ( $\alpha_{2}-$ and/or $\alpha_{3}-$ containing receptors) linked molecules than with the subtype associated with sedation ( $\alpha_{1}$-containing receptors). It is further noted that molecular dynamics simulation data of the complex (OXB2-GABA $\mathrm{R}$ ) shows adequate structural stability in aqueous environment. Moreover, relevant ADMET data is found adequate for further consideration.
\end{abstract}

Keywords: Benzemidazole, $\mathrm{GABA}_{\mathrm{A}}, \mathrm{GABA}_{\mathrm{A}}$ receptor, anxiety, docking 

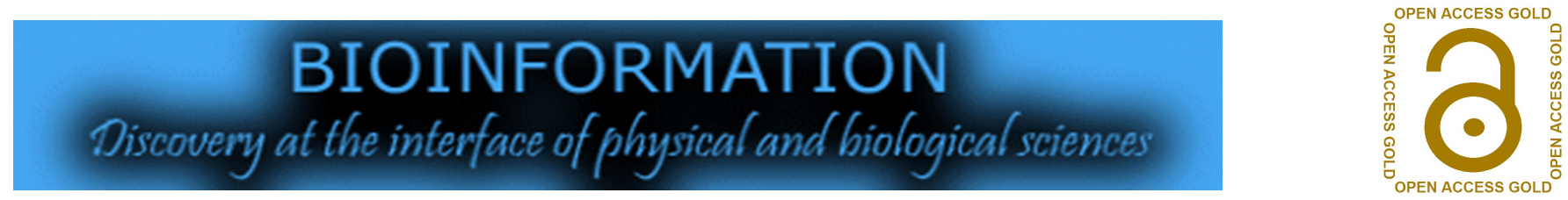

\section{Background:}

There is increasing interest to molecules containing heterocyclic ring, constituting the basic skeleton for a wide variety of compounds with industrial and pharmacological activities [1-2]. Heterocyclic compounds are the major chemicals, representing more than $60 \%$ of organic compounds and playing an important role in many biochemical processes [3]. Benzodiazepines are the main heterocyclic compounds used in medical therapy. These classes of psychoactive drugs are widely used for treatment of psychotropic diseases, especially Generalized Anxiety Disorder (GAD) [4-5]. Benzodiazepines are also known for their sedative and hypnotic properties [6-7], and also for their amnesic, muscle relaxant and sedative characteristics [8-9]. Benzodiazepines act allosterically to enhance the central $\gamma$-amino-butyric acid (GABA)mediated neurotransmission at the $\mathrm{GABA}_{\mathrm{A}}$ receptor [10]. $\mathrm{GABA}_{\mathrm{A}}$ receptors are ionotropic receptors and ligand-gated ion channel. Generally, $\mathrm{GABA}_{\mathrm{A}}$ receptors are pentameric proteins composed of different subunits $\left(\alpha_{1-6}, \beta_{1-3}, \gamma_{1-3}, \delta, \varepsilon, \pi\right.$ and $\left.\theta\right)$, $\alpha$ subunit being the most important one determining the pharmacology of the Benzodiazepines binding site [11]. The major Benzodiazepines sensitive $\mathrm{GABA}_{\mathrm{A}}$ receptor subtypes in the brain are $\alpha_{1} \beta_{\times} \gamma_{2}, \alpha_{2} \beta_{\times} \gamma_{2}$, $\alpha_{3} \beta_{\times} \gamma_{2}$ and $\alpha_{5} \beta_{x} \gamma_{2}$ and their distribution in the brain shows distinct regional variations [11]. Benzodiazepines are non-selective drugs and interact with all $\mathrm{GABA}_{\mathrm{A}}$ subtypes with equivalent affinity and efficacy, and consequently exert their therapeutic actions by modulating the function of $\mathrm{GABA}$ at $\mathrm{GABA}_{\mathrm{A}}$ receptors containing $\alpha_{1}$, or $\alpha_{2}, \alpha_{3}$ or $\alpha_{5}$ subunit [12-13].

Interest was given to delineate which $\alpha$-subunit-containing $\mathrm{GABA}_{\mathrm{A}}$ receptors subtypes are associated with particular aspects of the diverse pharmacology of nonselective benzodiazepines. The functional heterogeneity of $\mathrm{GABA}_{\mathrm{A}}$ receptor subtype was initially implied on the basis of regional differences in the expression of different $\alpha$ subunit containing $\mathrm{GABA}_{\mathrm{A}}$ receptors [14-15] along with the novel pharmacological profile of the $\alpha_{1}$-subtype preferring hypnotic benzodiazepines drugs [16]. The functions of different $\mathrm{GABA}_{\mathrm{A}}$ receptor populations have been further clarified by the use of transgenic mice as well as subtype-selective compounds [17-18]. Hence, it is widely accepted that $\alpha_{1}$-containing $\mathrm{GABA}_{\mathrm{A}}$ receptors play a role in the sedative properties of the nonselective benzodiazepines $[17 ; 19]$ and anxiolytic properties are mediated by $\alpha_{2}$ and/or $\alpha_{3}$ subtypes [18; 20-22].

Thereafter, great efforts are made to develop new anxiolytic drugs devoid of the sedative properties associated with classical benzodiazepines. In this regards, some anxioselective benzodiazepines were developed with much reduced sedative liability but have a lower intrinsic efficacy than existing benzodiazepines and therefore a limited clinical utility [23-24]. Currently, most studies focus on the development of compounds with subtype-selective efficacy, able to bind to all four subtypes, but with higher efficacy to $\alpha_{2-}$ and $\alpha_{3^{-}}$as compared to $\alpha_{1^{-}}$and $\alpha_{5-}$ containing receptors [25].

Benzimidazoles are heterocyclic aromatic compounds with large biological effects. Some benzimidazoles derivatives have shown a strong efficacy to cure psychotic disorders. Of particular interest, these compounds showed a good affinity to $\mathrm{GABA}_{\mathrm{A}}$ receptor with a clear selectivity to $\alpha_{2}$ and $\alpha_{3}$ subunits [26-29]. Recently, we have developed a new benzimidazole compound, 3-[2-(2-Amino- $1 \mathrm{H}-$ benzo[d]imidazol-1-yl)ethyl]-1,3-oxazolidin-2-one" $\left(\mathrm{OXB}_{2}\right)$, with a potential antidepressant / anxiolytic activities [30-31]. Therefore, it is of interest to study the binding capacity of "3-[2-(2-Amino- $1 \mathrm{H}-$ benzo[d]imidazol-1-yl)ethyl]-1,3-oxazolidin-2-one" $\left(\mathrm{OXB}_{2}\right)$, a newly synthesized and characterized Benzimidazole, on the active site of gamma-aminobutyric acid (GABA) located in the GABA type A receptor $\left(G A B A_{A} R\right)$ to compare with different $G A B A_{A}$ subtypes.

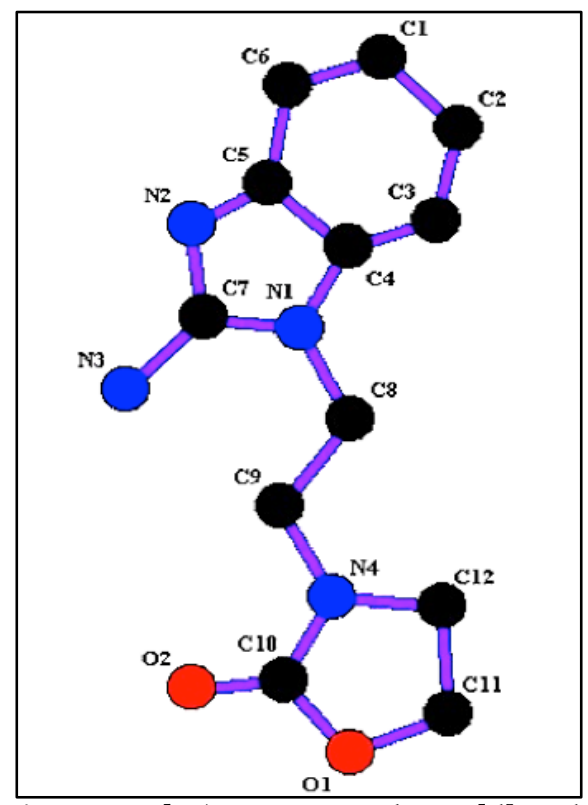

Figure 1: 3-[2-(2-Amino-1H-benzo[d]imidazol-1-yl) ethyl]-1,3oxazolidin-2-one $\left(\mathrm{OXB}_{2}\right)$ represent in vivo effect on $\mathrm{GABA}_{\mathrm{A}}$ receptors generated by Ligplot 

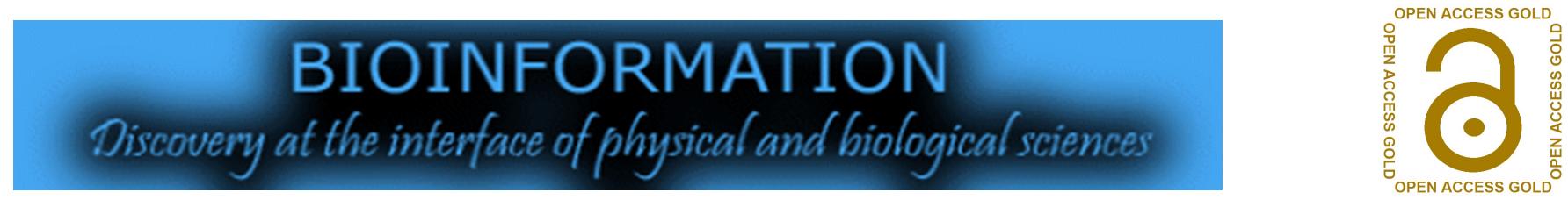

\section{Methodology:}

Synthesis of compounds:

$\mathrm{OXB}_{2}$ is a new Benzimidazole derivative synthesized by a new method PTC (Phase-Transfer Catalysis) by combining family of Benzemidazoles and Oxazolines. The purity of the newly synthesized compound was verified by melting point and on (Thin Layer Chromatography) TLC and the structure was determined by various analytical techniques such as IR spectral studies and $1 \mathrm{H}$ NMR (Spectroscopy Nuclear Magnetic Resonance). In $\mathrm{OXB}_{2}$, the Benzimidazole ring is almost planar with the largest deviation from the mean plane being 0.039 (2) $\AA$. However, the fused ring system is slightly folded at shared atoms with a dihedral angle of $3.4(1)^{\circ}$. In contrast, the Oxazoline ring displays a twisted conformation on the adjacent carbon atoms. Moreover, the mean plane through the Oxazoline cycle makes a dihedral angle of 57.4 (2) ${ }^{\circ}$ with the Benzimidazole ring. The molecules are linked together by two bifurcated $\mathrm{N}-\mathrm{H} \cdots \mathrm{O}$ and $\mathrm{C}-\mathrm{H} \cdots \mathrm{N}$ hydrogen bonds to form a threedimensional network (Figure 1). There is also a weak $\mathrm{C}-\mathrm{H} \cdots \pi$ (benzene) interaction, which contributes to the stability of the crystal packing arrangement [30-31].

\section{Structure of $\mathrm{GABA}_{\mathrm{A}}$ receptor:}

The crystal structure of the human's $G_{A B A_{A} R}$ was downloaded from RCSB database bearing the following crystallization specificities: Code PDB 4COF, which is the Crystal structure of a human gamma-aminobutyric acid receptor, the $\mathrm{GABA}_{\mathrm{A}} \mathrm{R}$-beta3 homopentamer published on 2014 by Miller, \& Aricescu, by x-ray diffraction with resolution in order to $2.97 \AA$. R-Value Free: 0.226 and R-Value Work: 0.205

The Unit cell parameters were as:

Length $[\AA]$ : $\mathrm{a}=174.10, \mathrm{~b}=108.90$ and $\mathrm{c}=207.44$.

Angles [ ${ }^{\circ}$ ]: $\alpha=90.00, \beta=107.43$ and $\gamma=90.00$.

As illustrated in Figure 2, the $\mathrm{GABA}_{\mathrm{A}}$ receptor is a molecular target for numerous CNS depressants including: benzodiazepines (e.g. librium, valium, medazolam), benzodiazepine- like hypnotics: (zolpidem, eszopiclone and zalepon which selectively bind to the $\alpha_{1}$ subunit of the $\mathrm{GABA}_{\mathrm{A}}$ receptor), Ethanol (at high \& low affinity binding sites), barbiturates and anesthetics (e.g. isoflurane) [14; 32]. As already mentioned, the $\mathrm{GABA}_{\mathrm{A}}$ receptors are composed by five subunits $(2 \alpha, 2 \beta$, and $1 \gamma)$. The GABA neurotransmitter bind in two sites (GABA site) localized between $\alpha$ and $\beta$ subunit (top view). In other hand benzodiazepines like midazolam and benzodiazepinelike hypnotics like zolpidem bind in (BDZ site) localized between $\alpha$ and $\gamma$ subunit (side view). Flumazenil (side view) is also BDZ receptor but has an antagonist characteristic, which can upset the effects of benzodiazepines and benzodiazepine-like hypnotics. The binding pocket is constructed from six regions, namely loops A-F. Experimental evidence reveals that the binding site in the $\mathrm{GABA}_{\mathrm{A}}$ receptor includes many residues (Table $\mathbf{1}$ )

\section{Molecular Docking:}

Molecular docking was used to evaluate the affinity of $\mathrm{OXB}_{2}$ to link to GABA $\left(\beta_{2} / \alpha_{1}, \beta_{2} / \alpha_{2}, \beta_{2} / \alpha_{3}\right)$ sites. The docking was performed on Autodock vina. The resulting structures were visualized using Chimera USCF [33] and PyMol [34], and 2D bond by LigPlus and Discovery Studio Visualization [35].

\section{Pharmacokinetic study:}

ADME-Tox (absorption, distribution, metabolism, elimination and toxicity) profile evaluation is widely used to evaluate the potential pharmacokinetic characteristics of chemical compounds describing the different processes followed by the chemical after administration. ADME-Tox properties of $\mathrm{OXB}_{2}$ were studied using Pre-ADME and ADMET-Sar server [36]. The interactions between $\mathrm{OXB}_{2}$ and blood proteins were assessed by 3D-QSAR model.

\section{Molecular dynamics:}

The molecular dynamics simulation has been carried out by GROMOS software using the server MDWeb [A] and gromacs [b]. The simulation was done by AMBER99SB Force Field and the following parameters: Time (ns) 10 and 50, $\Delta \mathrm{t}$ (ps) 0.1, Output Frequency (steps) 100, Force Constant $\left(\mathrm{Kcal} / \mathrm{mol}^{*} \AA^{2}\right)$ 40, Distance between Alpha Carbon Atoms $(\AA)$ 3.0. The mutations showed in the alignment results were investigated in MD to study their effects on the structure of the protein.

Table 1: amino acids and their characteristics in the binding site of GABA

\begin{tabular}{|c|c|}
\hline Amino acids characteristics & Noun and position \\
\hline Aromatic (Alpha and beta subunit) & $\alpha 1$ Phe $64, \beta 2 \mathrm{Tyr} 62, \beta 2 \mathrm{Tyr} 97$ and $\beta 2 \mathrm{Tyr} 205$ \\
\hline Hydroxylated (Alpha and beta subunit) & $\alpha 1$ Ser68, $\beta 2$ Thr160, $\beta 2$ Thr202, $\beta 2$ Ser204 and $\beta 2$ Ser209 \\
\hline Charged (Alpha and beta subunit) & $\alpha 1 \operatorname{Arg} 120, \alpha 1$ Asp183, $\alpha 1$ Arg66 and $\beta 2 A r g 207$ \\
\hline
\end{tabular}




\section{BIOINFORMATION \\ Discovery at the interface of physical and biological sciences}

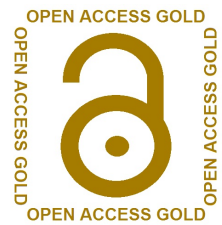

\section{Results \& Discussion:}

During last decades, pharmaceutical research has known a great evolution at both conceptual and methodological levels, using new technologies and innovative approaches. Bioinformatics and Cheminformatics tools have a special place in the process of valuing new synthetic components with cost and time gaining. In this study, bioinformatics tools were sued to evaluate the docking characteristics of $\mathrm{OXB}_{2}$, a newly synthesized molecule, on GABA $\left(\beta_{2} / \alpha_{1}, \beta_{2} / \alpha_{2}, \beta_{2} / \alpha_{3}\right)$ receptors, to evaluate the molecular dynamic of this link and to assess the ADEM-Tox profile of $\mathrm{OXB}_{2}$.

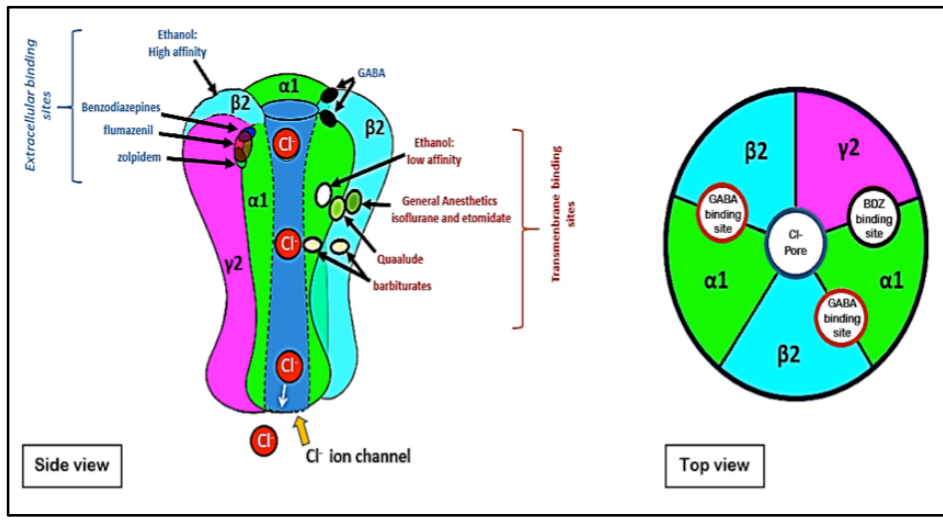

Figure 2: Structure of the $\mathrm{GABA}_{\mathrm{A}}$ receptor (side and top views) ${ }^{\prime \prime \prime}$ and position of the binding sites for different drugs.

Table 2: Docking results of $\mathrm{OXB}_{2}$ with $\mathrm{GABA}_{\mathrm{A}}$ isoforms $\left(\alpha_{1}, \alpha_{2}\right.$ and $\left.\alpha_{3}\right)$

\begin{tabular}{cc}
\hline$\alpha_{1}{ }^{*}$ & $-7.2 \mathrm{kcal} / \mathrm{mol}$ \\
\hline$\alpha_{2}{ }^{* *}$ & $-8.0 \mathrm{kcal} / \mathrm{mol}$ \\
\hline$\alpha_{3}{ }^{* *}$ & $-7.3 \mathrm{kcal} / \mathrm{mol}$ \\
\hline${ }^{*}$ Crystal structure ${ }^{* *}$ Modeled structure
\end{tabular}

$\operatorname{GABA}_{A}\left(2 \alpha_{2}, 2 \beta_{2}\right.$, and $\left.1 \gamma_{2}\right)$ and $\operatorname{GABA}_{\mathrm{A}}\left(2 \alpha_{3}, 2 \beta_{2}\right.$, and $\left.1 \gamma_{2}\right)$ were modeled using I-TASSER server, using $\operatorname{GABA}_{A}\left(2 \alpha_{1}, 2 \beta_{2}\right.$, and $\left.1 \gamma_{2}\right)$ (Id: $4 \mathrm{COF}$ ) as a template. The total energy variation showed that for the $3 \mathrm{GABA}_{\mathrm{A}}$ isoforms, the energy was around $-7 /-8 \mathrm{Kcal} / \mathrm{mol}$, indicating that $\mathrm{OXB}_{2}$ is able to link to both $\mathrm{GABA}_{\mathrm{A}}$ receptors. Specific energy liaison of $\mathrm{OXB}_{2}$ to the $3 \mathrm{GABA}_{A}$ isoforms is reported in Table 2 and showed that the high energy score was obtained with the isoform $\mathrm{GABA}_{\mathrm{A}}\left(\alpha_{2}\right)$ giving a score of $-8 \mathrm{kcal} / \mathrm{mol}$.

Interactions between $\mathrm{OXB}_{2}$ and $\mathrm{GABA}_{\mathrm{A}} \mathrm{R}\left(\alpha_{1}\right), \mathrm{GABA}_{\mathrm{A}} \mathrm{R}\left(\alpha_{2}\right)$ and $\mathrm{GABA}_{A} \mathrm{R}\left(\alpha_{3}\right)$ are represented in Figure 3. Overall, $\mathrm{OXB}_{2}$ component forms fewer bonds with the active sites and all formed bonds are non-covalent type. The absence of covalent bonds can be explained by compatibility of the shape of the $\mathrm{OXB}_{2}$ with the active site. The
Table 3 shows the residues involved in binding with the ligand and three isoforms of alpha subunit GABAA receptor. Eleven amino acids GLN64, PHE200, TYR62, ALA201, ALA88, TYR126, ARG114, VAL106, ARG114, LEU91 and ALA88 residues of template are involved in interaction.

Table 3: $\mathrm{GABA}_{\mathrm{A}}$ active site residues involved in docking interactions with the compounds.

\begin{tabular}{lrc}
\hline $\boldsymbol{\alpha}_{1}$ & $\boldsymbol{\alpha}_{2}$ & $\boldsymbol{\alpha}_{3}$ \\
\hline GLN64 & ALA88 & ARG114 \\
PHE200 & TYR126 & LEU91 \\
TYR62 & ARG114 & ALA88 \\
ALA201 & VAL106 & LEU91 \\
& ASN138 & ASP39 \\
& THR140 & \\
\hline
\end{tabular}

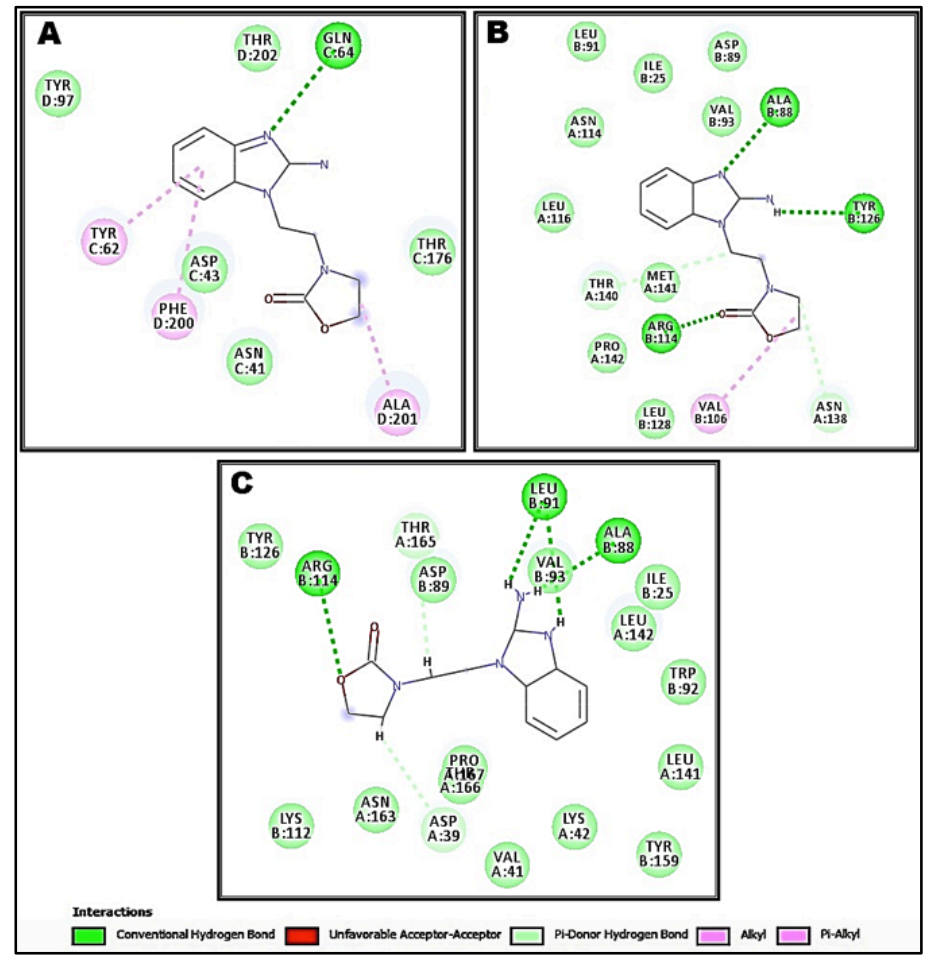

Figure 3: Schematic representation of interactions observed between $\mathrm{OXB}_{2}$ and $\mathrm{GABA}_{\mathrm{A}}\left(\alpha_{1}\right){ }^{*} \mathrm{~A}^{*}, \mathrm{GABA}_{\mathrm{A}}\left(\alpha_{2}\right){ }^{*} \mathrm{~B}^{*}$ and $\mathrm{GABA}_{\mathrm{A}}$ $\left(\alpha_{3}\right){ }^{*} C^{*}$ generated by discovery studio visualize

The proposed binding mode $\mathrm{OXB}_{2}$ revealed an affinity value of -7.2 $\mathrm{kcal} / \mathrm{mol}$ with the isoforms $\alpha_{1}$. The $\mathrm{N}$-atoms of $\mathrm{OXB}_{2}$ interacted with active sites of GABA $\left(\alpha_{1}\right)$ by forming H-bond with GLN64 at distances of $2.69996 \mathrm{~A}^{\circ}$. Also, Pi-Alkyl type of interaction observed 

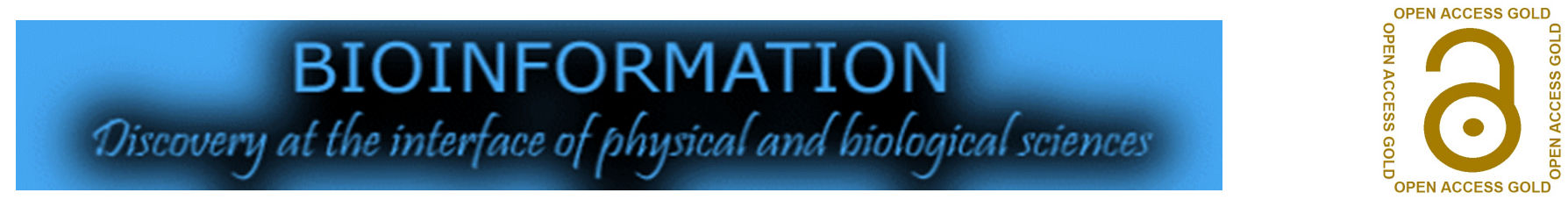

between aromatic rings and TYR62 and PHE200 with distances $4.34717 \mathrm{~A}^{\circ}$ and $4.8423 \mathrm{~A}^{\circ}$ respectively. Alkyl type of interaction was observed between (ALA201) and "carbon 11" of the ligand with bond lengths of $3.8367 \mathrm{~A}^{\circ}$ (Fig. 3A). In $\mathrm{GABA}_{\mathrm{A}}\left(\alpha_{2}\right)$ isoform, the proposed binding mode $\mathrm{OXB}_{2}$ revealed an affinity value of -8 $\mathrm{kcal} / \mathrm{mol}$. $\mathrm{OXB}_{2}$ interact with many amino acids residues by forming hydrogen bonds with ALA88 (3.35142A $\left.{ }^{\circ}\right)$, TYR126 $\left(2.46278 \mathrm{~A}^{\circ}\right), \operatorname{ARG} 114\left(2.75004 \mathrm{~A}^{\circ}\right), \operatorname{THR} 140\left(3.40151 \mathrm{~A}^{\circ}\right)$ and ASN138 $\left(4.97569 \mathrm{~A}^{\circ}\right)$. Also Alkyl type of interaction was observed between VAL 106 and carbon 12 of the ligand with bond lengths of $3.8367 \mathrm{~A}^{\circ}$ (Fig. 3B). Otherwise, $\mathrm{OXB}_{2}$ revealed an affinity value of -7.3 $\mathrm{kcal} / \mathrm{mol}$ with the isoforms of $\mathrm{GABA}_{\mathrm{A}}\left(\alpha_{3}\right)$. Exclusively, H-bond type of interaction was indicated with different amino acids. LEU91 forms two bonds with $\mathrm{NH}-\mathrm{OXB}_{2}$ with bond lengths of $2.61522 \mathrm{~A}^{\circ}$ and $2.46548 \mathrm{~A}^{\circ}$. Also ARG114, THR 165, ASP39 and ALA88 form the same type of bond with $\mathrm{OXB}_{2}$ with distance $2.26162 \mathrm{~A}^{\circ}, 2.82758$ $\mathrm{A}^{\circ}, 3.04107 \mathrm{~A}^{\circ}$ and $2.38929 \mathrm{~A}^{\circ}$ respectively (Figure 3C).

The non-covalent bonds established between the chemical compound and $\mathrm{GABA}_{\mathrm{A}}$ receptors are of particular interest to favor the placement of the proper ligand at the active site with competition and reversibility, whereas covalent bonds are highly stable and mostly associated with irreversible effects [37]. The liaison between $\mathrm{OXB}_{2}$ and $\mathrm{GABA}_{\mathrm{A}}$ receptors exhibited an endothermic reaction, which thermodynamically favors the good orientation of the compound in the system due to the increase in the enthalpy effect according to the law of Internal Energy [38]. The increase in Van Der Waals (VdW) energy is an obvious result as the new components are characterized by the presence of nitrogen atom and core aromatics of 5, making the attractive effect of the components more significant [39].

It's widely accepted that knowledge at an atomic level of the structural and dynamic aspects of organized systems is particularly important for better understanding the functions of these complex molecular structures. In many cases, obtaining the microscopic details by conventional experimental techniques proves impossible. However, the true explosion of the computerized means initiated for about ten years, and the development of efficient algorithms, make possible the study of supra molecular assemblies of increasing complexity by the methods of theoretical chemistry [40].

The complexes obtained by molecular docking were submitted to a simulation of $20 \mathrm{~ns}$ (Figure 4). Molecular dynamic results show stability of protein-ligand complex, characterized by thermal stability during the simulation conditions. The fluctuation of the protein complex is more stable for both complex and proteins; however the binding energy is more suitable for the complex than the protein alone. The simulations are done in a constant pressure system for the different cell dimension, which allowed having a prototypical simulation of the cellular activity during the whole dynamic simulation period. The energies of bonds, partially and VdW are very close, which lead to a high Van der Waals energy, just like a large number of hydrogen bonds since they pull the atoms closer than their normal Van der Waals contact distance.

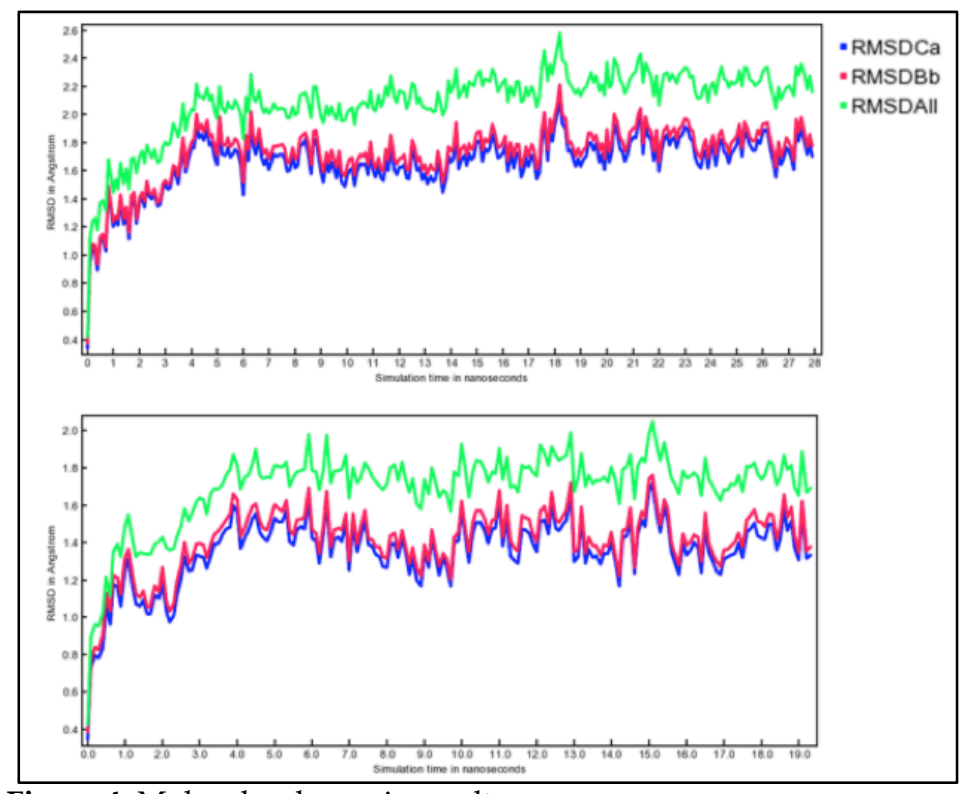

Figure 4: Molecular dynamic results

The total potential energies were calculated for each snapshot (Figure 5) and showed a fluctuation of about $1000 \mathrm{kcal} / \mathrm{mol}$ (about $0.5 \%$ of the total potential energy), indicating the stabilization of all the systems in MD simulations. In addition, the potential energies of complex models for each ligand subtype were quite similar, suggesting that the influence of local mutations on potential energy could be neglected in MD simulations. RMSD values were further calculated for each snapshot to study the relative movement of the backbone atoms of the proteins and ligands. RMSD values fluctuated largely when whole protein structures were considered in the calculation. Most of the RMSD values were less than $2 \AA$, and some of them even reached $0.6 \AA$ (the complex model), indicating that the receptors showed less significant structural changes during the simulations. Since most parts of the complexes are less rigid and stable, the fluctuation of the RMSD values is mainly due to the loop. Thus, the RMSD values, excluding the complex, the structures were recalculated in Figure 4. The new RMSD values were 


\section{BIOINFORMATION \\ Discovery at the interface of physical and biological sciences}

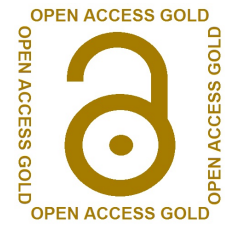

generally less than $6 \AA$, demonstrating that the high RMSD values of the full-length receptors were attributed to the high flexibility of loops telling the active site.

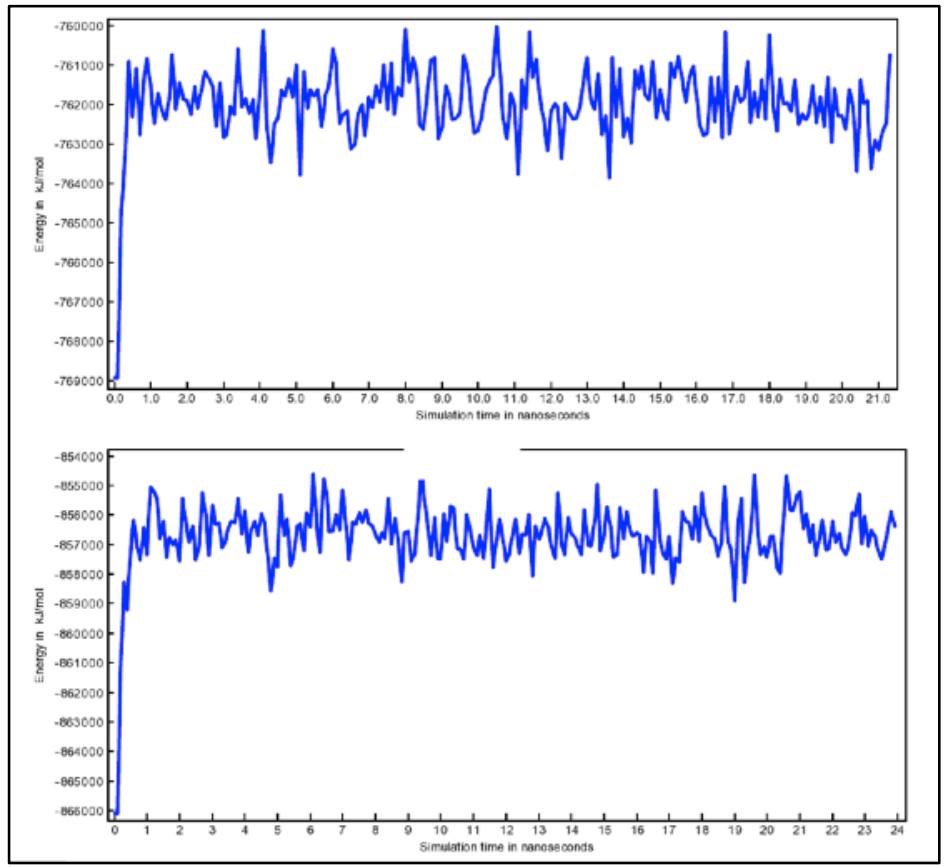

Figure 5: Total energy of systems

A high value of factor $B$ indicates more flexibility, while a low value of factor B indicates more stability. The helices had very low B-factor values, but the loops had moderate or high B-factor values, indicating large conformational changes in the loop regions during the MD simulations. These results were consistent with the inference of the RMSD values and explained that the high RMSD value of the complex was caused by a major conformational change, such as rotation. Although the flexibility of the loop has decreased the stability of the system, it would not affect intercomplex interactions because the loop was located far from the link interface. Thus, the reliability of further analysis can be guaranteed. $\Delta \mathrm{EvdW}$ and $\triangle$ Eelec oppose binding, but $\Delta \mathrm{GGB}$ enhances binding to the complex by switching from $\mathrm{CP}$ to AP ligand, while $\triangle \mathrm{EvdW}$ and $\triangle$ Eelec improve binding. The sum of AEvdW and AEelec could overcome the term AGBG and cause the net link change. Decomposition analysis of binding energies In order to explore how mutations influence binding energies, binding energies are decomposed into each residue.

The pharmacodynamics and pharmacokinetic of newly synthesized drugs are of a great interest to evaluate the target and the undesirable effects and to appreciate the metabolization, biodistribution, elimination and toxicity of the drug and its derivatives. In this study, the ADME-Tox profile of $\mathrm{OXB}_{2}$ was evaluated and results are reported in Table 4. In ADME-Tox analysis, the main parameter is the characterization of blood-brain barrier (BBB), evaluating the ability of drugs to cross this barrier and go insight the brain [41]. The role of BBB is to maintain brain homeostasis and to protect nerve tissue from circulating blood microorganisms, toxins, cellular factors and humoral immune system [42]. However, the presence of BBB prevents the treatment of many diseases of the central nervous system, and therefore in the perspective of psychotropic diseases therapy, all potential drugs have to cross the BBB and link to the target sites. ADME-Tox results showed that BBB permeability index was 0.554267 , considered as medium to low [43], suggesting that $\mathrm{OXB}_{2}$ is able to cross the $\mathrm{BBB}$ and acts on $\mathrm{GABA}_{\mathrm{A}}$ receptors as target sites. Other important pharmacokinetic parameters were also predicted by Pre-ADME and ADMET-Sar and showed that $\mathrm{OXB}_{2}$ exhibited no AMES mutagenic and carcinogenic effects by Ames assay and possessed better human intestinal absorption. $\mathrm{OXB}_{2}$ had also Middle $\mathrm{Caco} 2$ permeability had a well human intestinal absorption. Predictive results showed that $\mathrm{OXB}_{2}$ weakly bounds to Plasma protein binding (PPB) and had lower MDCK permeability. These results suggest that $\mathrm{OXB}_{2}$ ligand has adequate pharmacokinetic characteristics and could be a promising candidate to be used as a drug.

Table 4: ADMET prediction of $\mathrm{OXB}_{2}$

\begin{tabular}{llll}
\hline Parameter & $\begin{array}{l}\text { Value / } \\
\text { Predictive result }\end{array}$ & Parameter & $\begin{array}{l}\text { Value / } \\
\text { Predictive result }\end{array}$ \\
\hline Ames mutatest & Negative & HIA & 96.623102 \\
SK $\log$ S pure & -1.9298 & CYP3A4 substrate & Weakly \\
SK $\log$ S buffer & -1.59987 & CYP3A4 inhibition & Non \\
SK $\log$ P value & 1.15268 & CYP2D6 substrate & Non \\
SK $\log$ D value & 1.15268 & CYP2D6 inhibition & Non \\
Skin Permeability & -4.1626 & CYP2C9 inhibition & Non \\
Pure water solubility $\mathrm{mg} / 1$ & 2894.73 & CYP2C19 inhibition & Non \\
\hline
\end{tabular}




\section{BIOINFORMATION}

\section{Discovery at the interface of physical and biological sciences}

\begin{tabular}{llll}
\hline Plasma Protein Binding & 52.137421 & Caco2 & 19.5815 \\
Pgp inhibition & Non & Buffer solubility mg/1 & 6187.83 \\
MDCK & 17.4024 & BBB & 0.554267 \\
\hline
\end{tabular}

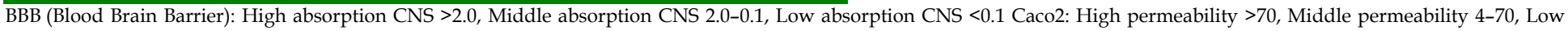

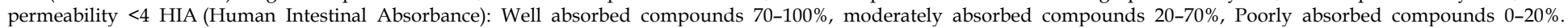
PPB (Plasma Protein Binding): Strongly Bound >90\%, Weakly Bound <90\%, MDCK: Higher permeability >500, Medium Permeability $25-500$, lower permeability <25.

\section{Conclusion:}

We document the molecular docking analysis of $\alpha_{2}$-containing $\mathrm{GABA}_{\mathrm{A}}$ receptors with a benzimidazole derivative for further consideration.

\section{References:}

[1] Southon I.W \& Buckingham J, Chapman \& Hall, New York 1989.

[2] Komeilizadeh H, Iranien J of Pharm Res. 2006 4: 229.

[3] Brandi A et al. Chem Rev. 2003 103: 1213 [PMID: 12683782].

[4] Gorman JM. J Clin Psychiatry. 2003 2: 24. [PMID: 12625796].

[5] Gorman JK CNS Spectrums. 2005 10: 14.

[6] Mitte, K et al. J Clin Psychopharmacol. 2005 25: 141. [PMID: 15738745].

[7] Holbrook et al. CMAJ, 2000 162: 225 [PMID: 10674059].

[8] Morin, A.K et al. Pharmacotherapy, 2007 27: 89 [PMID: 17192164].

[9] Olkkola, K.T. \& Ahonen, J. Exp. Pharmacol. 2008 182: 335 [PMID: 18175099].

[10] Stewart, S.A. J Clin Psychiatry, 2005 2: 9. [PMID: 15762814].

[11] E.N. Peterson, Drugs Future 1987 12: 1043.

[12] E.A. Barnard et al. Pharmacol. Rev. 1998 50: 291. [PMID: 9647870].

[13] Sieghart, W. Pharmacol. Rev. 1995 47: 181[PMID: 7568326].

[14] Olsen, R.W \& Sieghart, W. Pharmacol. Rev. 2008 60: 243 [PMID: 18790874].

[15] Fritschy, JM \& Mohler, H. J Comp Neurol. 1995 359: 154 [PMID: 8557845].

[16] Sieghart, W \& Sperk, G. Curr Top Med Chem. 2002 2: 795 [PMID: 12171572].

[17] Benavides et al. J Pharmacol Exp Ther. 1988 245: 1033 [PMID: 2838599].

[18] McKernan, R.M et al. Nat Neurosci. 2000 3: 587 [PMID: 10816315].

[19] Dias, R. et al. J Neurosci. 2005 25: 10682 [PMID: 16291941].

[20] Rudolph, U et al. Nature. 1999 401: 796 [PMID: 10548105].

[21] Atack, J.R. et al. Br J Pharmacol. 2005 144: 357 [PMID: 15655523].

[22] Lo $\square \mathrm{w}$, K et al. Science. 2000 290: 131 [PMID: 11021797].

[23] Haefely, W et al. Trends Pharmacol Sci. 1990 11: 452 [PMID: 1980040].
[24] Atack, JR. Curr Drug Targets CNS Neurol Disord. 2003 2: 213 [PMID: 12871032].

[25] Atack JR. Exp Opin. Investig Drugs. 2005 14: 601 [PMID: 15926867].

[26] de Haas S.L et al. J Psychopharmacol. 2008 22: 2 [PMID: 18187530].

[27] Atack JR. Adv Pharmacol. 2009 57: 137 [PMID: 20230761].

[28] Atack JR. Curr Top Med Chem. 2011 11: 1176 [PMID: 21050172].

[29] Da Settimo F et al. Curr Med Chem. 2007 14: 2680 [PMID: 17979718].

[30] Bouayyadi A et al. World Journal of Pharmaceutical Research. 2016 5: 61.

[31] Bouayyadi A et al. IUCr Data. 2016 1: 12.

[32] Uwe Rudolph \& Hanns Mohler. Annul Rev Pharmacol Toxicol. 2014 54: 483 [PMID: 24160694].

[33] Pettersen E.F et al. J Comput Chem. 2004 25: 1605 [PMID: 15264254].

[34] DeLano, WL. CCP4 Newsletter on protein crystallography. 2002 40: 82.

[35] BIOVIA DS. Discovery studio visualizer, Release 2017, San Diego: Dassault Systèmes, 2016.

[36] Lee SK et al. EuroQSAR Designing Drugs and Crop Protectants: processes, problems and solutions. 2002 2003: 418420.

[37] Richard B. Silverman \& Mark W. Holladay. The Organic Chemistry of Drug Design and Drug Action. 2014 5: p 239.

[38] Manabendra N et al. Nat Commun. 2017 8: 2180 [PMID: 29259191].

[39] Kunal Roy et al. Understanding the Basics of QSAR for Applications in Pharmaceutical Sciences and Risk Assessment, Academic Press. 2015 1: 1-46

[40] Beyond the Molecular Frontier Challenges for Chemistry and Chemical Engineering National Research Council (US) Committee on Challenges for the Chemical Sciences in the 21st Century. Washington (DC): National Academies Press (US). 2003 Chap 6 ISBN-10: 0-309-08477-6.

[41] Konstantin V Balakin. PHARMACEUTCAL DABA MINING. Approches and Applications for Drug Discovery. 2009 3: 94.

[42] Inge S Zuhorn. Tissue Barriers. 2016 4: 1 [PMID: 27141428]. 


\section{BIOINFORMATION \\ Disseovery at the interface of physieal and biological Sceiencess}

[43] Ma, X., Chen, C. \& Yang, J. Acta Pharmacol Sin 2005 26: 500

[PMID: 15780201].

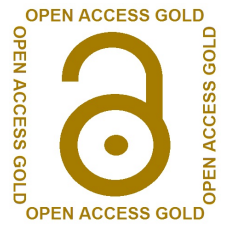

Edited by P Kangueane

Citation: Bouayyadi et al. Bioinformation 16(8): 611-619 (2020)

License statement: This is an Open Access article which permits unrestricted use, distribution, and reproduction in any medium, provided the original work is properly credited. This is distributed under the terms of the Creative Commons Attribution License

\section{Articles published in BIOINFORMATION are open for relevant post publication comments and criticisms, which will be published immediately linking to the original article for FREE of cost without open access charges. Comments should be concise, coherent and critical in less than 1000 words.}




\section{BIOINFORMATION}

Discovery at the interface of physical and biological sciences
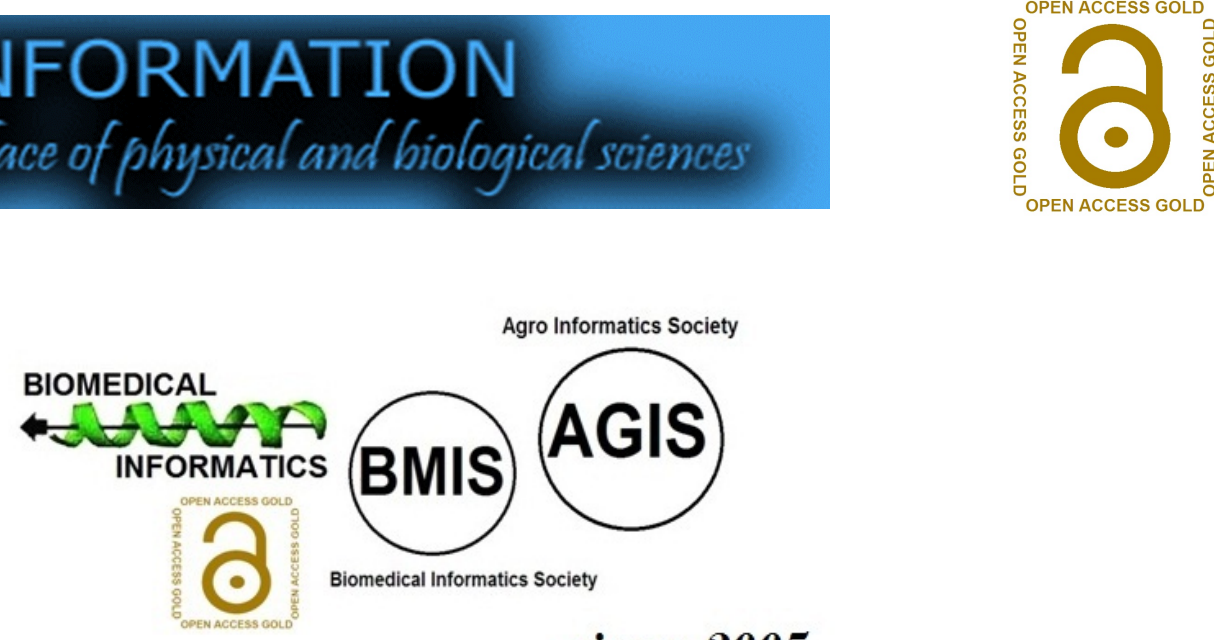

since 2005

\section{BIOINFORMATION}

Discovery at the interf ace of physical and biological sciencess

\section{indexed in}

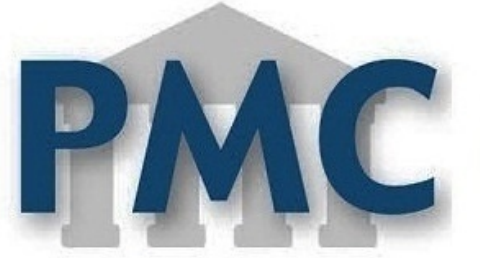

PublMed

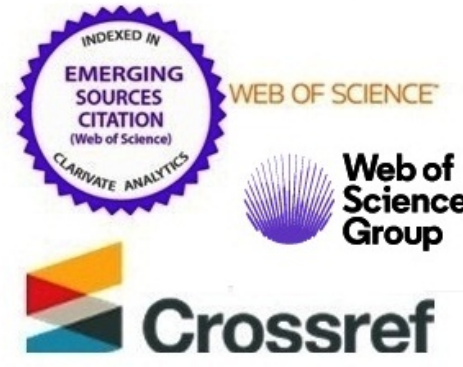

EBSCO

ResearchGate
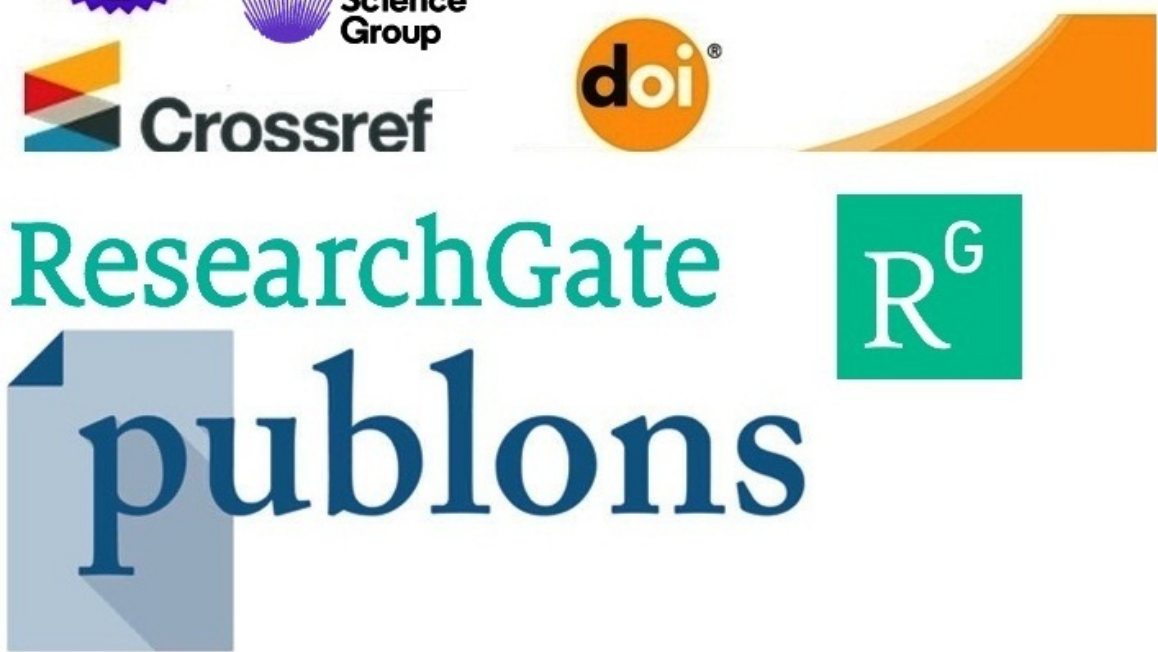